\title{
À MODA DE FOUCAULT: UM EXAME DAS ESTRATÉGIAS ARQUEOLÓGICA E GENEALÓGICA DE INVESTIGAÇÃO
}

Hermano Roberto Thiry-Cherques

Foucault está na moda. Talvez nunca tenha deixado de estar. Mas apenas parte da sua obra é discutida. As questões relacionadas ao poder têm sido consideradas como sua única contribuição. Injustamente. Em que pese a revolução causada até mesmo em disciplinas tão áridas como as das ciências de gestão (ver Motta e Acadipani, 2004), o trabalho de Foucault transcende os resultados materiais que alcançou. Para além da tematização de questões concernentes à loucura, à disciplina, à moral, seus estudos lançaram uma nova luz sobre as possibilidades epistemológicas no campo das ciências humanas e sociais. Não somente infletiram o rumo das pesquisas qualitativas, como colocaram em questão a objetividade das investigações empíricas.

Os escritos deixados por Michel Foucault são extremamente fecundos, mas, em geral, complexos. A vertente epistemológica não constitui exceção. Também neste terreno as interpretações e possibilidades são tão ricas que levam a equívocos quando se pretende sintetizá-las. Por isto, não tenho a pretensão de apresentar uma visão 
metodológica acabada, que seria a de Foucault. O que proponho neste texto é uma interpretação, entre outras possíveis, do que entendo como o componente essencial da sua forma de pesquisar. Limito-me a trazer à discussão a maneira de Foucault abordar as questões que se propôs. Pretendo contribuir para trazer para o campo de investigação a que me dedico, o das ciências da gestão (ver Calás e Smircich, 1999), o exemplo do trabalho de pesquisa a fundo, da visão inovadora sobre o instituído; uma forma de investigar à moda de Foucault.

Dificilmente se poderia falar de um único procedimento de pesquisa que tenha sido repetido por Foucault. Seu legado epistemológico é de outra natureza. Desdobra-se em três dimensões: a do dever para com a verdade, acima e além dos compromissos com métodos e filiações ideológicas; a do esforço analítico exaustivo, sem pressupostos e sem fronteiras; e a da busca de um olhar novo sobre os 216 temas e as teorias.

O compromisso intelectual com a verdade é pessoal. Cada pesquisador deve assumi-lo como puder. As leituras dos textos de Foucault e dos estudos sobre sua obra constituem um exemplo, não um culto, de como se quis fazer. Sua forma de ver é única, não admite imitações. Seu método é variável; não pode ser esquematizado. Mas da prática investigativa de Foucault podemos aprender muito. Aprendemos o desassombro ante o estabelecido. Aprendemos que toda teoria é provisória; que todo método depende do estado da pesquisa; e que os conceitos são úteis enquanto clarificam e organizam os dados, enquanto servem para encontrar relações. Aprendemos que diferentes objetos e diferentes investigações determinam adaptações, mudanças, análises fragmentárias.

A epistemologia de Foucault pode ser dividida em dois ciclos: o da arqueologia, que tem sua origem na questão kantiana da determinação da possibilidade de conhecer, e 
o da genealogia, que deriva da ideia de Nietzsche da impossibilidade de nos libertarmos da nossa própria condição e da nossa história. Uma terceira parte da sua obra, a da ética, não oferece grandes inovações em termos epistemológicos: é um roteiro de autoelucidação, que vai desde a moral, entendida como os valores e as regras que emanam dos aparelhos institucionais, até a maneira como cada um de nós se constitui como sujeito ético de um código.

$\mathrm{O}$ ciclo arqueológico compreende:

1) a História da loucura, de 1961 (Foucault, 2002b), tese de doutorado de Foucault, em que o autor analisa comparativamente a loucura no Renascimento (delírio, consciência trágica), no período clássico (questão social, condenação ética, aprisionamento), do século XIX (enfermidade, fenômeno instrumentalizável) até a psicanálise e os poetas loucos. Constata que a loucura é um objeto permanente, e que o tempo modifica apenas o conhecimento que se tem dela.

2) O nascimento da clínica, de 1963 (Foucault, 1998), em que Foucault procura mostrar que as figuras do saber e da linguagem obedecem à mesma lei profunda, a uma estrutura que acentua as teorias, as práticas, os discursos e a sensibilidade de uma determinada época.

3) As palavras e as coisas, de 1966 (Foucault, 2002a), em que ele desenvolve uma análise das determinações não evidentes (estruturas) dos saberes sobre a linguagem, a vida e a economia; que se apresentam como jogo de aparências no Renascimento, como reduplicação no período clássico e a repetição antropológica na época moderna. Trata-se de uma arqueologia das ciências humanas, em que Foucault recusa considerar os métodos morais da modernidade como um progresso e vê o homem do humanismo, evanescente ante a linguagem e os signos da sua representação, como fonte e produto dos seus saberes.

4) A arqueologia do saber, de 1969 (Foucault, 2004), em que Foucault recupera, critica e reordena o roteiro metodo- 
lógico que utilizara até então, e que neste texto vai apresentado como a forma arqueológica de investigar.

O ciclo genealógico tem início com

5) Vigiar e punir, de 1974 (Foucault, 1977). Trata-se de uma genealogia do confinamento, onde a prisão é vista como modalidade punitiva e como instrumento funcional de conhecimento da conduta humana e do desenvolvimento das técnicas disciplinares, do poder sobre o corpo, derivado da vigilância contínua e dos sistemas de punição e recompensa. Essa perspectiva é estendida ao poder e à organização societária contemporânea (o hospital, as escolas, as organizações formais).

O ciclo prossegue com

6) A vontade de saber, de 1976, primeiro tomo da História da sexualidade (2001f). Nela Foucault reverte a ideia da sexualidade como objeto de censura com vistas ao esforço produtivo das classes operárias. Analisa os sistemas de inter218 dição como peças de um dispositivo de incitação à verbalização do desejo, e a sexualidade como "invenção" do Ocidente e como causalidade difusa dos meios e dos sistemas de saber.

O ciclo genealógico completa-se com

7) a genealogia do desejo e da sexualidade secreta como construção mítica do pensamento moderno, ideias desenvolvidas em $O$ uso dos prazeres e em $O$ cuidado de si, de 1984, segundo e terceiros tomos de História da sexualidade (Foucault, 2001f). Nestes livros, Foucault estuda a ética na Antiguidade grega e romana, e analisa as relações entre os indivíduos e o corpo, o cuidado de si e o modelo cristão da ordenação do desejo.

A estratégia expositiva de Foucault é a de jogar com o efeito surpresa. Quando descobrimos que a descrição, que passa por uma narração objetiva, nos é totalmente desprovida de sentido, anula-se para o leitor a pretensão de que o saber contemporâneo é uma verdade objetiva. Nesse movi- 
mento abrem-se novas perspectivas, novos horizontes de investigação. Ele procura demonstrar, através de ilustrações históricas (por exemplo, a de uma execução pública em 1757), que o que nós pensamos ser aspectos comuns da vida humana, ao longo do tempo, não são mais do que construtos formados por práticas sociais específicas (Rowlinson e Carter, 2002, p. 534).

Foucault busca o não familiar; o estranho; a rejeição da continuidade do objeto, do progresso histórico, da causalidade. Sua estratégia metodológica é indeterminável: ela vai sendo elaborada à medida que a pesquisa avança, os objetos requerem, os conceitos permitem. Nos itens subsequentes examino os componentes dessa estratégia 1) enquanto processo de investigação; 2) enquanto arqueologia; 3) enquanto genealogia; e 4) enquanto analítica interpretativa. Concluo 5) com o exame dos paralelismos entre outras modalidades de investigação e a de Foucault.

\section{0 processo}

O processo de investigação utilizado por Foucault evolui de pesquisa para pesquisa. Não mantém uma sequência rígida, mas abarca passos essenciais. São eles:

1) a identificação das práticas discursivas e dos atos materiais (não discursivos). Não interessa a verdade, mas o que é dito, nem o sentido, mas o enunciado. Isso implica reconhecer os saberes existentes na regularidade: as regras de formação dos conceitos, dos objetos, das estratégias, das ações, ou seja, as práticas não discursivas e das instituições a eles associados.

2) a determinação das descontinuidades, isto é, da emergência e do desaparecimento de conformações das subjetividades e da objetividade social expressa nos saberes, ou seja, os limiares epistemológicos das epistemes, dos dispositivos, em cada segmento (momento) descontínuo. Isso faz aflorar os estratos acumulados, justapostos pelo tempo; 
3) a análise, e não a interpretação, desses elementos, que se dá simultaneamente a cada identificação e a cada determinação. Sinteticamente, trata-se da criação de um quadro explicativo da articulação entre a seriação dos discursos e as práticas não discursivas.

Descrito assim, resumidamente, o processo de investigação desenvolvido por Foucault aparece hermético, inacessível ao pesquisador comum. Mas não se trata disto. É que pela novidade do que propunha, pelo inconformismo ante os métodos estabelecidos, derivados do marxismo, da fenomenologia e do estruturalismo, o autor foi compelido não só a inventar procedimentos, mas, também, a cunhar termos que pudessem nomear as descobertas epistemológicas que ia fazendo.

Foucault preferiu a profundidade à amplitude. Trabalhou sobre poucos temas. A loucura, o surgimento dos saberes, o poder, as relações com o corpo são os mais 220 conhecidos. Sua preocupação foi a de como as estruturas do conhecimento e os modos de compreender se alteram segundo época e lugar. A profundidade e a fecundidade de Foucault foram possíveis graças à originalidade dos processos de investigação que adotou. Seu compromisso nunca foi com o esquema e, nem mesmo, com o rigor. Foi com os princípios de análise, com as correspondências, com a minúcia e com a descoberta. O que ele pratica em seu trabalho de pesquisa é, antes de tudo, uma decifração.

Epistemologicamente, a obra de Foucault se cinde em duas vertentes: a da arqueologia e a da genealogia. Mas não existe, em Foucault, um método arqueológico e outro genealógico (Dreyfus e Rabinow, 1992, pp. 155-185). Ocorre que, a partir de As palavras e as coisas, Foucault abdicou de enunciar uma verdade profunda, uma estrutura que repousaria para além das aparências. Ele tentou, ao contrário, interpretar as aparências como um conjunto ordenado de práticas históricas que determinam os conteúdos. 
Tentou apreender a singularidade dos acontecimentos fora de toda finalidade uniforme. Procurou restituir os acontecimentos na contingência da nossa (atual) singularidade (Foucault, 1984).

\section{Arqueologia, episteme, saber}

Por arqueologia, Foucault entende o desvelamento da circunstância histórica que faz necessária certa forma de pensamento.

A arqueologia, à diferença da história factual - que não é capaz de dar conta do conceito e da sua formação em uma época - procura marcar as mutações; não os momentos primeiros, que são sempre relativos (Foucault, 2001e, p. 145). Procura explorar as diferenças entre conceitos, objetos, estilos, teorias; entre as formas de racionalidade que o sujeito humano aplicava a si mesmo (Foucault, 2001d, pp. 318-320).

A arqueologia também difere da história das ciências. Ela se interessa pelos saberes que transcendem e englobam a ciência do momento, que não são o senso comum ou o bom senso, mas os conhecimentos, mesmo aqueles (des)qualificados como ingênuos ou não científicos, os saberes particulares, as formas de pensar das pessoas (do paciente, não a do médico, por exemplo).

A diferença entre a arqueologia e a história das ciências ultrapassa a simples dilatação do campo epistemológico: o que estabelece a distância entre a história, a história das ciências e a arqueologia é que a arqueologia tem como fundamento a ideia de que uma época só pode ser entendida a partir dela mesma (Foucault, 1979, p. 167). Uma arqueologia é um estudo das condições filosóficas, técnicas, institucionais, sociais, econômicas, políticas etc. de emergência dos discursos do saber em geral e da articulação entre eles em uma época. Informa sobre uma coerência, sobre uma episteme em um momento determinado (Ewald, 2004, p. 31). 
Foucault faz uma distinção entre a "percepção", ou "sensibilidade" (ver Machado, 1981, p. 63, nota 1), o saber, o discurso geral no nível das pessoas e das instituições, e o "conhecimento", a elaboração teórica, o discurso científico ou que tem a pretensão à cientificidade (Machado, 1981, p. 116). O saber, a forma como uma determinada época sentiu um objeto, não é, necessariamente, nem um progresso, nem um atraso em relação à forma como o objeto foi entendido em alguma outra época. O saber tem uma positividade - posit (põnere), posto, factual -, uma ordem interna constitutiva (episteme) anterior à ordenação do discurso, porque o configura em uma determinada época, de forma que só pode ser entendido como e a partir dele mesmo.

Por exemplo, em As palavras e as coisas, Foucault mostra como, pelo fato de vivermos, trabalharmos e nos expressarmos de determinada forma, construímos, em cada época e lugar, representações sobre a vida, o trabalho e a linguagem.

222 As representações que são reproduzidas (reduplicadas) como objeto das ciências humanas. A reduplicação, diferente do signo, "representa", isto é, liga a ideia de uma coisa com a ideia de outra coisa. Por isto, os modelos constituintes das ciências humanas são os pares conceituais: função \& norma; conflito \& regra; significação \& sistema. O privilégio de um deles definirá arqueologicamente a psicologia, a sociologia, o estudo da literatura e dos mitos e assim por diante.

O saber, ou os saberes, constitui o objeto das quatro grandes arqueologias de Foucault. Mas a arqueologia não é um método. Não é algo cujos princípios básicos possibilitarão, pela aplicação a diferentes objetos de pesquisa, uma série de análises empíricas. A arqueologia se caracteriza pela variação constante dos seus princípios, pela permanente redefinição dos seus objetivos, pela mudança no sistema de argumentação (Machado, 1981, p. 57). O livro que Foucault publica ao término do que denominamos ciclo arqueológico, A arqueologia do saber, não relata propriamente o método 
utilizado nas pesquisas anteriores. Antes propõe o que deveria, idealmente, ser o método arqueológico. E que não será posto em prática. Porque se, de um lado, o livro encerra o ciclo arqueológico, de outro, consolida princípios de análise que irão ser obedecidos no ciclo seguinte: o da genealogia.

\section{Genealogia, dispositivo, poder}

A abordagem genealógica deriva de uma convicção que Foucault toma de Nietzsche: a de que o que aconteceu só pode ser compreendido em termos do presente. Não se trata do abandono da arqueologia como abordagem, mas de uma alteração do foco em direção ao presente e para determinados objetos. Foucault depura as continuidades das práticas culturais que genealogia isola; identifica as descontinuidades evidenciadas em discursos-objeto. Não há uma ruptura entre a arqueologia e a genealogia.

O próprio Foucault sustentou que há uma continuidade na sua abordagem, tendo variado tão somente os "domínios” da genealogia: a arqueologia é o método próprio à análise da discursividade local. A genealogia é a tática, que a partir da discursividade local descrita, ativa os saberes libertos da sujeição que emergem desta discursividade. E por girar em torno de um tema único, o do poder, e de uma relação privilegiada, a que se dá entre o poder e o saber, a genealogia tem, como veremos mais adiante, contornos epistemológicos diversos da arqueologia, que examino a seguir (Foucault, 1979, p. 167).

\section{Como uma arqueologia}

Os estudos levados a cabo na forma epistemológica desenvolvida por Foucault são únicos em vários sentidos. $\mathrm{O}$ principal deles é o da ligação particular entre o processo investigativo e o método, que vai sendo desenvolvido segundo os requerimentos do objeto e as descobertas do investigador. Isto não impede que possamos seguir, não os passos - seria 
inadequado ou, mesmo, impossível listar itens de uma rotina para apreender um processo que, por natureza, se vai formando na medida em que avança - , mas indicações, tanto para uma arqueologia como para uma genealogia realizada à moda de Foucault.

\section{0 documento}

O processo arqueológico consiste basicamente em uma análise documental que tem como propósito individualizar formações discursivas, isolar pertinências, descrever relações, definir conjuntos e as séries de enunciados que formam o discurso. Os documentos são entendidos não como textos a serem interpretados, mas como monumentos a serem analisados. $\mathrm{O}$ olhar de Foucault se dirige para o que ele denomina de arquivo: os discursos efetivamente pronunciados, considerados não somente como um conjunto de acontecimentos que teriam ocorrido uma vez por todas, mas como 224 um conjunto que continua a funcionar, a se transformar através da história, possibilitando o surgimento de outros discursos (Foucault, 2001a).

\section{0 arquivo}

Os arquivos são, primeiramente, os documentos literários e não literários de uma época. Mais tarde Foucault incorporará aos arquivos as práticas não discursivas: as maneiras de ser e de se comportar que são ainda as nossas. Nesta primeira fase, que vai até os anos 1970, o arquivo contém a episteme: o conjunto de relações que liga os diferentes tipos de discurso, correspondentes a uma época. Depois, integrará os dispositivos, que incluem o social não discursivo.

\section{A episteme}

A episteme não é o conhecimento comum ou a teoria dominante. Nada tem a ver com o Geist, o espírito (da época ou do lugar), nem com a consciência coletiva. É diferente da 
estrutura e do sistema. A episteme é a articulação de múltiplos sistemas e estruturas em oposições, distâncias, relações de múltiplos discursos científicos. É o paradigma segundo o qual se estruturam, em uma determinada época, os múltiplos saberes, que por esta razão compartilham, a despeito de suas especificidades e dos diferentes objetos, determinadas formas ou características gerais. A episteme é epocal: os diversos saberes de uma época se articulam em torno de e a partir de um a priori (a condição de possibilidade destes saberes, como na representação na Idade Clássica).

\section{O dispositivo}

Com a evolução das suas investigações, Foucault abandona o conceito da episteme em favor de uma noção mais ampla: a de dispositivo. A episteme é a parte meramente discursiva do dispositivo. Este abarca, além dos discursos, as práticas, as instituições, as táticas. Inclui a episteme e "todo social não discursivo".

Trata-se de um processo evolutivo. Foucault inicialmente trabalhara com o conceito de estrutura. Depois desenvolveu o de episteme. O conceito de dispositivo - o termo é tirado do anti-Édipo (Deleuze e Guattari, 1976) -, contém a mesma ideia básica: a de uma formação de elementos heterogêneos que explicam as condições de possibilidade (o quadro) dos saberes (conceitos e percepções) de uma época. Mas, ao incluir as instâncias institucionais, como igreja, asilo, medicina, prisão, família, passa a identificar

um conjunto deliberadamente heterogêneo, abarcando discursos, instituições, arranjos arquitetônicos, decisões normativas, leis, medidas administrativas, enunciados científicos, proposições filosóficas, morais, filantrópicas, em breve: o dito como o não dito. O dispositivo é a rede que se pode estender entre estes elementos (Foucault, 2001f, pp. 82-ss.). 


\section{0 não discursivo}

Foucault se interroga sobre a natureza e a função estratégica dos diferentes dispositivos. Procura dar conta do sentido do conceito tal como é definido pelos discursos da própria época. Do espaço colateral ao discurso (eventos políticos, instituições, processos econômicos) e do espaço correlativo (lugares, pontos de vista) nele contido. As noções de não discursivo e de dispositivo remetem para interações com outras análises, como a dos aparelhos ideológicos do Estado, de Althusser (1987).

\section{Descontinuidade}

Estas análises demonstram como o surgimento de uma nova episteme ou de um novo dispositivo estabelece uma ruptura gnosiológica que suprime os métodos e pressupostos cognitivos anteriores, e dispõe outros, que os absorvem e superam. Mediante esses conceitos, Foucault demonstrou 226 que o tempo do saber e o tempo do discurso não são dispostos como o tempo vivido. Eles apresentam descontinuidades e transformações específicas (Foucault, 2001a, p. 148), passagens de uma episteme a outra, de um dispositivo a outro.

A descontinuidade se verifica quando surge uma nova forma de discurso e um novo tipo de instituição social, uma nova sensibilidade, uma reação ante o problema econômico, uma nova ética do trabalho; quando, enfim, surge um novo dispositivo (Dreyfus e Rabinow, 1992, p. 21). Mas a descontinuidade não estabelece uma ruptura absoluta entre épocas. Existem sempre condições de possibilidades antecedentes. As formações se superpõem. As fronteiras são deslocadas, assimétricas. Em um tempo não previsível e difícil de se recuperar, "sente-se" que há uma violação de categorias. Por exemplo, quando, em um determinado momento, a sensibilidade da época se deu conta de que os loucos e os delinquentes eram categorias distintas, trata- 
das de uma mesma maneira, que não podiam ficar presos juntos (Foucault, 2002b).

\section{Decifração}

Dessa perspectiva, trata-se de determinar os efeitos, não a cadeia continuada de causalidade. A descontinuidade é uma "ínfima ruptura", uma "mutação". Não a mudança no quadro, mas a mudança do quadro. Por exemplo, como é demonstrado em As palavras e as coisas: a filologia, a biologia e a economia política não substituem a gramática geral, a história natural e a análise das riquezas, senão que ocupam espaços nos quais estes saberes antes não existiam. Na perspectiva de Foucault, não é o investigador que determina, $a$ priori, a descontinuidade: a própria especificidade do objeto de investigação determina os limites espaço-temporais do campo investigado. A descontinuidade deve ser revelada, descoberta, e não estabelecida.

\section{0 discurso}

O discurso para Foucault é um conjunto de enunciados que obedecem a regras de funcionamento comuns. Existe uma "ordem do discurso" própria a um período particular, que põe em evidência os mecanismos de organização do real (saberes, estratégias, práticas). Para Foucault, não se deve reduzir o discurso a textos cujos traços seriam lidos a partir da sua estrutura interna, como se nada existisse fora dele. O discurso é uma prática. A arqueologia articula as "formações discursivas"; as "práticas discursivas" com práticas econômicas, políticas e sociais.

Não se trata de constituir um corpus, mas de selecionar discursos. O corpus é indefinido: jamais se chegará a constituir o conjunto de discursos pronunciados sobre a loucura, ou sobre a prisão, ou sobre o poder disciplinar, ainda que limitando a investigação a uma época e a um lugar (Foucault, 2001c, pp. 27-33). 
A determinação do discurso consiste em: 1) descobrir qual a "ordem do discurso" em uma época; 2) descrever as transformações dos tipos de discurso; 3) interrogar-se sobre as condições de emergência dos elementos discursivos.

\section{Análise}

A análise na forma arqueológica, além da óbvia escolha do documento a ser analisado, implica em uma atitude anterior, que compreende um trabalho negativo, e outro, positivo.

O trabalho negativo da arqueologia consiste em: 1) manter em suspenso as unidades aceitas, as formas imediatas de continuidade como a tradição, ou atribuição de origem, a influência ou processo causal. 2) Descartar o desenvolvimento e a evolução ou a relação a um único e mesmo principio gerador; a origem "secreta" ou o começo/recomeço oculto, que deve ser buscado e repetido. 3) Desconsiderar tanto a mentalidade ou uma comunidade de sentido para uma épo228 ca determinada, compreendendo a análise das totalidades culturais (visões de mundo, tipos ideais, Geist singular de épocas), como o livro (a unidade material do discurso) e a obra, isto é, a resultante de uma interpretação que a dota de uma suposta homogeneidade (inconsciente do autor), o "já-dito" ou o discurso sem corpo, que deve ser interpretado.

O trabalho positivo da arqueologia consiste em, a partir da descrição dos acontecimentos discursivos, construir uma teoria que: 1) limite as unidades discursivas, 2) determine as regras que obedecem estas unidades, 3) indique a forma como se dividem em enunciados, e que 4) se articulam em um domínio espaço-temporal, constituído de todos os enunciados efetivos em uma dispersão de acontecimentos.

Em termos práticos, isto significa iniciar a investigação aceitando um recorte provisório. É necessário escolher um domínio de relações numerosas e discursos pouco formalizados que encerrem enunciados que têm por objeto um determinado campo de conhecimento. 
A partir desta escolha é que se determinam os conjuntos de articulação dos enunciados que encerram as formações discursivas: 1) os espaços nos quais os objetos se relacionam; 2) as regras de inclusão, de repartição e de inter-relacionamento dos enunciados; 3) a emergência dos conceitos; e as 4) possibilidades estratégicas (temas e teorias) em jogo.

Conforme a escolha dos discursos que serão objeto de estudo, a tônica da análise recairá prioritariamente sobre um desses elementos: sobre um ou vários objetos; sobre as modalidades enunciativas; sobre a formação dos conceitos; ou sobre os temas e teorias. Mas, qualquer que seja a tônica da análise, cada uma dessas formações deve ser considerada, primeiro individualmente, depois em sua articulação como enunciados e, finalmente, enquanto discurso.

\section{Objetos}

Quanto aos objetos, a definição da formação discursiva compreende relacionar o objeto ao conjunto de regras de formação do discurso, ao nexo que forma uma regularidade (regra) enquanto objeto possível do discurso. Isto se faz mediante a análise do próprio discurso, buscando as regras da prática discursiva (inclusão, repartição, articulação) que conformam o objeto de que falam. Procedimento que consiste em: 1) Demarcar as superfícies da sua emergência, as condições temporais, diferentes segundo sociedades, épocas, formas de discurso. 2) Descrever as instâncias de delimitação dos objetos, como, por exemplo, instituição, regulamento, competência reconhecida; centro de decisão, processos, formas de comportamento, normas etc., que permitem ao objeto aparecer. 3) Analisar as grades de especificação, como separação, oposição, associação, reagrupamento, classificação, derivação, hierarquização, repetição etc. 4) Determinar que relações permitiram a formação do conjunto de objetos diversos. 
Não se trata de privilegiar objetos, mas de determinar a maneira como os objetos são formados; isto é, a articulação entre as instâncias anteriores - emergência, delimitação, especificação - que determinam o feixe de relações que o discurso deve efetuar para poder falar destes ou daqueles objetos. Não a interpretação da linguagem, das circunstâncias, mas a análise do próprio discurso.

\section{Modalidades enunciativas}

Quanto às modalidades enunciativas, a análise deve dar conta de três instâncias: 1) a instância de quem fala, isto é, sua linguagem, profissão, função, legitimidade, representação; em outros termos, analisar em nome de quem se pronuncia. 2) A instância dos lugares institucionais do discurso, isto é, do seu campo documentário. E, 3) a instância da situação do sujeito em relação aos domínios (grupos de objetos); ou seja, o que observa? o que anota? quais os intermediários? 230 qual sua posição na rede de informações (como emissor e receptor)? qual o seu sistema de registro?

\section{Conceitos}

Foucault produz um deslocamento importante no estudo da formação do conceito: ele o torna independente da racionalidade científica. Para esse autor, o conceito e sua formação já não se circunscrevem à epistemologia ou ao conhecimento; ao contrário, se abrem para a percepção, para o saber em geral, que inclui a ciência, mas não se cinge a ela (Machado, 1981, p. 82). Por isso, a análise dos conceitos deve dar conta: 1) da forma como se sucedem, 2) das formas de coexistência dos conceitos e 3) dos procedimentos de intervenção.

A análise das formas de sucessão compreende: 1) a disposição das séries enunciativas (inferências, implicações sucessivas, raciocínios demonstrativos, descrições, esquemas de generalização ou de especificação); 2) a análise dos tipos 
de correlações (hipótese - verificação; assertiva - crítica; lei geral - aplicações particulares) e 3) dos esquemas retóricos (encadeamento das descrições, deduções, definições de grupos de enunciados).

A análise das formas de coexistência dos conceitos abarca a identificação: 1) do campo de presenças, das "verdades" aceitas; 2) do campo de concomitância, da "validade" de enunciados que pertencem a domínios diversos, mas que valem como analogias, premissas, modelos, instâncias superiores; e 3) do domínio de memória, dos "laços" entre os conceitos (filiação, gênese, transformação, continuidade, descontinuidade).

Finalmente, a análise dos procedimentos de intervenção dos conceitos compreende: 1) as técnicas de reescrita (por exemplo, de linear à matricial, como quando se constroem quadros e diagramas); 2) os métodos de transcrição, isto é, da linguagem utilizada; 3) os modos de tradução (quantitativo para qualitativo; refinamento; delimitação; de um campo a outro); e 4) os métodos de sistematização (por exemplo, o reordenamento).

As relações entre as formas de sucessão, as formas de coexistência dos conceitos e os procedimentos de intervenção constituem o que Foucault denomina de sistema de formação conceitual.

\section{Estratégias}

Quanto às estratégias, parte-se do princípio de que nos discursos, os objetos, as modalidades enunciativas e os conceitos são ordenados segundo temas, teorias, concepções. Para identificá-las, devemos procurar os pontos de difração (de passagem) de uma série coerente de elementos a outra, as analogias, as oposições, as complementaridades entre discursos contemporâneos e as práticas não discursivas, que possam fundamentar as escolhas teóricas ou temáticas. 


\section{Enunciado}

A análise das formações discursivas se completa pela crítica dos enunciados que conformam e caracterizam o discurso. $\mathrm{O}$ procedimento permite compreender o enunciado na sua singularidade de acontecimento, nas correlações com outros enunciados e nas suas relações não discursivas de ordem técnica, econômica, social e política.

Tal como entendido por Foucault, enunciado é uma noção ampla que tanto excede quanto abarca as proposições lógicas. Isso porque pode haver enunciado sem proposição lógica legítima, como as frases gramaticais e os atos de fala. E também porque há enunciados que são menos do que frases; uma lista classificatória, um livro contábil ou um gráfico são enunciados.

Foucault não se interessa pela escrita institucionalizada. Dedica-se a "tudo que pode escapar a isso, o discurso anônimo, o discurso do cotidiano, [...] o que dizem os lou-

232 cos, [...] os operários [...] é esta linguagem que me interessa cada vez mais" (Foucault, 2001c, p. 56). O enunciado é um conjunto de signos, que pode ser uma frase ou uma proposição, mas considerada no nível da sua existência. É o nuntus, o mensageiro, o que dá a saber.

O enunciado é não oculto e não visível de imediato. Não oculto, obviamente, porque deve ter sido proferido. Não visível, porque ele se esconde: 1) dentro de frases e proposições; 2) atrás da estrutura significante da linguagem, dos significantes e dos significados (palavras, símbolos); 3) atrás de outras análises da linguagem; e 4) se cruza com as análises linguísticas e lógicas.

A análise enunciativa não é uma interpretação (no sentido de buscar o que o enunciado "quer significar") de um não dito reprimido: é um descobrimento. Para descobrir o enunciado é necessário: 1) fixar o vocabulário que permite a um conjunto de signos estar em relação com um domínio de objetos; prescrever uma posição a qualquer sujeito possí- 
vel, estar dotado de uma materialidade repetível; 2) definir as condições em que se realizou a função que deu à série de signos uma existência específica; 3) identificar os domínios não discursivos (instituições, práticas, acontecimentos políticos, processos etc.); 4) definir formas específicas de articulação: o lugar em que os efeitos, as simbolizações, podem ser situados não como a prática, o não discursivo, determinou o discurso, mas como faz parte das suas condições de emergência, inserção e funcionamento; 5) afirmar em que domínio (conjunto de historicidades diversas) das práticas, das instituições, das relações sociais etc. pode articular-se uma formação discursiva.

\section{Como uma genealogia}

A genealogia é uma modalidade de investigação que se opõe à unicidade da narração histórica e da origem das coisas e dos atos: ela trabalha a partir da diversidade e da dispersão, da aleatoriedade dos começos e dos acidentes, da singularidade dos acontecimentos (Ewald, 2004, p. 31).

\section{Transição}

Até a Arqueologia do saber, Foucault se detém na análise do discurso. "Não procuro", diz ele "por baixo do discurso o que é o pensamento dos homens mas tento tomar o discurso em sua existência manifesta, como uma prática que obedece a regras". Foucault analisa o próprio discurso, ou seja, as práticas discursivas que são intermediárias entre as palavras e as coisas, as práticas a partir das quais se pode definir o que são as coisas e situar o uso das palavras. Buscando

ver de que palavras e, consequentemente, de que conceitos, se dispunham, quais eram as regras de utilização dessas palavras. As regras de formação de objetos, que não são as regras de utilização das palavras, regras de formação de conceitos, que não são leis de 
sintaxe, regras de formação das teorias, que não são regras de dedução nem regras retóricas, que explicam como uma coisa é vista ou omitida, que tal palavra seja empregada com tal significação em um tal tipo de frase (Foucault, 1967; 2001d, p. 140).

Esta forma de abordar os textos não corresponde a uma teoria universal, mas a uma descrição das diferentes formas históricas das práticas discursivas (Dreyfus e Rabinow, 1992, p. 9). Por exemplo, em As palavras e as coisas, Foucault demonstra que existiu nos séculos XVII e XVIII um tipo de discurso que era a um só tempo descritivo e classificador. Já no século XIX, novos tipos de discurso se formaram, entre eles o das ciências humanas. Depois de ter analisado os tipos de discurso, o autor procura ver como eles puderam se formar historicamente e com quais realidades históricas se articulam.

A partir dos anos 1970, a análise do discurso perde a centralidade que tinha no trabalho de Foucault. Não porque a abandone, mas porque ele dá preferência ao que denomina de "dinástica do saber": a relação que existe entre esses grandes tipos de discurso e as condições econômicas, políticas, históricas, culturais de seu aparecimento e da sua formação (Foucault, 2001b, p. 49). É este procedimento genealógico que adotará então.

\section{Nietzsche}

O método genealógico, no sentido que lhe dá Nietzsche (1990), baseia-se na ideia da exploração em busca da gênese do próprio pensar. Já Husserl (2003) trabalha a noção de uma lógica genética, com o esclarecimento da origem de um conceito a partir de um pré-conceito. Heidegger (1993) a entendia como o "regresso ao fundamento"; a razão da razão; a volta aos gregos em busca não do fundamento, mas da investigação sobre o fundar. 
A constatação de Nietzsche de que, em cada época e em cada circunstância, as palavras não guardam o mesmo sentido, os desejos não guardam a mesma direção, as ideias a mesma lógica (Foucault, 1979, p. 15), leva Foucault a fixar a sua análise não na evolução, mas nos cenários e nos pontos de ruptura. $\mathrm{O}$ autor foca os objetos e os acontecimentos que não parecem ter história para buscar o que condiciona, limita e institucionaliza as formações discursivas; para diagnosticar as relações entre o poder, o saber e o corpo na sociedade moderna. Para demonstrar que o saber se encontra sempre preso aos conflitos do poder, em uma fecundação recíproca e incontrolável. Para evidenciar que a dominação não é uma "apropriação" intencional, mas fruto das práticas (disposições, manobras, técnicas) relacionais incondicionadas (Dreyfus e Rabinow, 1992, pp. 155-ss).

Foucault sustenta que as condições de possibilidade dos saberes não se encontram nas relações destes com os poderes instituídos, como o do Estado, mas na articulação entre poderes locais, específicos, moleculares. Que os poderes (e os saberes) não estão localizados em nenhum ponto específico da estrutura social; que não existe "o" poder, mas práticas e relações de poder. Que o poder é uma relação, não uma coisa. A partir da evidência de que o discurso é saber e é poder, Foucault demonstra que o poder dita a verdade; que o poder não tem centro: ele circula, é relacional, funciona em cadeias, que não é atribuível a uma classe, nem ao Estado. Enfim, que o poder "microfísico" produz o real.

\section{Interstícios}

A genealogia apoia-se sobre a arqueologia e a completa. Para a genealogia, como para a arqueologia, não existem essências fixas, leis básicas, finalidades metafísicas. O que há são recorrências e jogos. Não progressos e seriações. O presente é a resultante de deslocamentos imperceptíveis e de contiguidades sutis. A abordagem genealógica absorve a 
análise arqueológica em uma dimensão interpretativa. Em uma análise não do que aconteceu, da história, mas do que nos aconteceu, do que aconteceu ao objeto. Nela, o pesquisador está "situado": ele deve compreender a significação das práticas culturais da sua época desde o interior mesmo dessas práticas.

Quando examinamos os saberes, nós substituímos sua inteligibilidade interna pela inteligibilidade que ocupam no seio da formação discursiva (arqueologia). A cada vez temos que superar o "trauma do referente". Uma vez cumprida esta tarefa, a genealogia se pergunta sobre o papel histórico e político dos saberes (Dreyfus e Rabinow, 1992, p. 10).

A análise genealógica é tanto descendente (do poder do Estado até as suas ramificações mais remotas) como ascendente (dos poderes dispersos e ínfimos até a sua condensação em relações dominantes). Parte da especificidade da questão colocada e verifica até onde o poder e o saber se 236 enraízam nos estratos mais gerais da vida social, nos interstícios das suas relações.

A genealogia recusa a pesquisa da origem (Ursprung, a procedência). Não se trata de recuar no tempo para mostrar que o passado subsiste (continuidade) no presente. Tampouco tem por fim reencontrar as raízes de nossa identidade "mas fazer aparecer todas as descontinuidades que nos atravessam" (Foucault, 1979, p. 35). A análise genealógica é um misto de busca do tronco (Herkunft, a proveniência) de onde provém um caráter, um conceito e os acontecimentos que os formaram: os desvios, as inversões, os acidentes que deram nascimento ao que existe e tem valor para nós, e de busca da emergência (Entestehung), do processo de surgimento, não o ponto de aparecimento (a potência antecipadora de um sentido). Uma emergência que sempre se dá em um interstício: no vazio entre o bem e o mal, o belo e o feio, o necessário e o contingente, o essencial e o supérfluo. 
Como a arqueologia, a genealogia é constituída por formas de decifração, de descoberta. Examina a superfície sem aventar interpretações obscuras e profundas. O itinerário metodológico de Foucault permanece o mesmo: não é buscando o subjacente, a estrutura, a consciência, o espírito, que se encontra a visão profunda das coisas; ao contrário, é examinando detalhadamente, à distância e em ângulo adequado, que se alcança destacar o verdadeiro do fundo nebuloso.

\section{Decifração}

Também como a arqueologia, a análise genealógica congrega a investigação minuciosa do saber geral e a decifração das memórias particulares, específicas. Não procura o saber erudito ou científico, mas aquilo que se tem por conhecido. Difere da arqueologia ao partir do interesse da atualidade, ao centrar-se na dissecação teórica das relações de poder no nível micro, e ao considerar o saber como positividade (prática, materialidade, acontecimento) enquanto peça do dispositivo das práticas políticas disciplinares.

O processo genealógico estabelece as correspondências de sentido entre a atualidade e o passado imediato ou remoto. O roteiro da investigação compõe-se de dois passos fundamentais: 1) a identificação de componentes situacionais, de condições presentes, e 2) a interrogação sistemática de como este estado presente chegou a ser.

A genealogia não interpreta, porque não há nada a interpretar e porque todo movimento de compreensão já é interpretação (Foucault, 1979); limita-se a descrever a história das interpretações. Ela nos desvela os universais do nosso pensamento humanista enquanto produto de interpretações que nos foram culturalmente impostas (Dreyfus e Rabinow, 1992, p. 160).

A identificação do ponto de relevância contemporâneo não é um "presentismo", pois não deriva de uma análise 
conjuntural, senão do entendimento do que é essencial em nosso presente. Tampouco a análise é a desconstrução finalística de tudo que antecedeu, mas a busca no passado (e não nas origens remotas) dos elementos que nos permitam visualizar a história não do passado, mas do que (nos) acontece: a história do presente.

\section{Analítica}

São três as vertentes analíticas de Foucault:

1) uma ontologia histórica de nós mesmos enquanto sujeitos e objetos do conhecimento, nas nossas relações com a verdade, que nos permite constituir-nos como sujeitos do conhecimento, correspondendo ao ciclo de investigações que se encerra com a Arqueologia do saber.

2) A genealogia do poder, que considera cada um de nós em nossas relações em um campo de poder, onde nos constituímos em sujeitos que agem sobre os outros, e que corres238 ponde às investigações que deram origem a Vigiar e punir.

3) E uma genealogia da relação com a moral, que nos considera enquanto agentes éticos, correspondendo à História da sexualidade.

Qualquer que seja a vertente analítica, o objetivo principal é explicitar, aquém do nível dos conceitos dos objetos teóricos e dos métodos, o que pode explicar como (arqueologia) e por que (genealogia) as ciências do homem apareceram.

A trajetória metodológica do ciclo da arqueologia transcende ao de uma análise conceitual dos objetos. Ela é uma análise do discurso, das práticas não discursivas, dos saberes. Uma análise das descontinuidades, da episteme. O que faz a arqueologia, e o que seguirá fazendo a genealogia, é deslocar critérios, seja os das análises convencionais, seja os das escolhas de conceitos, objetos, relações, dominâncias. Foucault estabelece condições de existência, não de validade. Considera a verdade como produção histórica, ava- 
lia saberes, e não ciências, analisa formações do discurso, e não o conteúdo do dito e do registrado.

A genealogia introduz algumas novidades metodológicas. Dá maior ênfase ao exame do não discursivo, nos espaços institucionais de controle, e, na continuidade da positividade com seus objetos, conceitos, métodos e atores, nas rupturas e nas regras de transformação. O seu campo de análise gira em torno da questão do poder, da relação entre o poder e o saber e das relações entre o poder, o saber e o corpo enquanto objeto de controle de gestos, atitudes, hábitos, comportamentos. Situa o saber como elemento de um dispositivo de natureza essencialmente estratégica, como positividade (prática, materialidade, acontecimento) enquanto peça do dispositivo das práticas políticas disciplinares (Machado, 1981, p. X).

O que faz a genealogia é tomar o saber enquanto conhecimento como peça de um dispositivo político que, enquanto dispositivo, se articula com a estrutura econômica. Mais especificamente, a questão da genealogia é a de como se formam domínios de saber a partir de práticas políticas disciplinares (organização do espaço, controle do tempo, vigilância e registro dos conhecimentos). Ela se presta a investigações históricas delimitadas, a análises particularizadas, que não podem e não devem ser aplicadas indistintamente a objetos que não o poder, o saber, o corpo (Machado, 1981, pp. 194-198). Mas, da mesma forma que podemos, utilizando as categorias da arqueologia, proceder a análises diversas das de Foucault, podemos, utilizando a forma de colocar a questão epistemológica da genealogia, operar sobre questões diversas da tríade poder/saber/corpo.

\section{Analítica interpretativa}

Tanto na arqueologia como na genealogia, a análise de Foucault não é uma interpretação. Não se trata de apoderar- 
-se de um sistema de regras que não tem em si significação essencial e lhe impor uma direção, submetê-lo a um novo jogo de regras. O que Foucault realiza é uma "analítica interpretativa” (Dreyfus e Rabinow, 1992, pp. 179-ss). Ele procura fazer aparecer como emergências no teatro dos acontecimentos sociais, as ideias, os ideais, os conceitos, mas também os sentimentos, os instintos, a fisiologia.

É uma analítica que abarca a questão fundamental de Kant sobre as condições que tornam possível e que limitam a análise racional, e a inquietação de Heidegger, sobre o fundamento transcendental no sujeito da consciência que define as condições existenciais, a-históricas e transculturais, que são necessárias ao homem para que se conheça. Mas que, ao contrário de Kant e de Heidegger, Foucault não postula uma teoria universal sobre a consciência humana: quer, tão somente, desvelar as práticas culturais que determinam o que somos.

240 Para Foucault, a interpretação isenta é impossível, tanto no sentido de Heidegger (de que nós estamos condenados a interpretar a história em função das práticas da nossa época), como no sentido de Nietzsche (de que, uma vez que nós somos o que a história fez de nós, é impossível construirmos uma imagem sobre o passado e sobre o presente destacada da nossa condição e da nossa história). Por isso a genealogia não interpreta: ela descreve a história das interpretações e nos revela que os universais do nosso pensamento humanista são o produto da aparição contingente de interpretações que nos foram culturalmente impostos (Dreyfus e Rabinow, 1992, p. 160).

A analítica de Foucault não é um “comentário” sobre o sentido aparente de um texto ou de uma prática, como na hermenêutica heideggeriana. Ele não pretende, como pretenderam Heidegger e Freud, que exista uma continuidade entre a inteligibilidade ordinária e a inteligibilidade profunda (que a primeira tende a mascarar e a distorcer). O que 
podemos descobrir através da interpretação - e suprimir, seja o traumatismo, seja a angústia existencial - é que a significação das práticas se alcança pela interpretação das próprias práticas. Foucault propõe uma explicação da situação presente mediante a decifração das regras que determinam ou regem os discursos e as práticas não discursivas efetivos.

\section{Paralelismos}

Dizia-se que Foucault era um dos estruturalistas; isto é, que dava primazia à estrutura inconsciente sobre a ação inconsciente, ao macro sobre o micro, às condicionantes sobre o voluntarismo (Ribeiro, 2004, p. 44). Mas é igualmente conhecida a assertiva de Foucault: "Nunca fui freudiano, nunca fui marxista e jamais fui estruturalista" (Foucault, 2001d, p. 312). De fato, Foucault não foi estruturalista, embora tenha mantido alguns dos pressupostos estruturalistas. Tampouco aderiu à fenomenologia, ainda que recuperasse princípios e formas de ver de Heidegger. Ele é crítico em um sentido diferente: ele critica as condições de possibilidade de um determinado saber, da constituição do poder (ver Billouet, 2003, p. 37).

Com o marxismo e o pensamento historicista, a ruptura é absoluta: Foucault nega qualquer possibilidade de uma ordem essencial na história. Já com o estruturalismo ele mantém relação "ao mesmo tempo de distância e de reduplicação" (Foucault, 2001a, p. 60). "Ao lado dele, não nele" (Foucault, 2001e, p. 152). A reduplicação está no fato de que Foucault não define a priori o campo de aplicação da pesquisa; o autor se dirige à esfera discursiva, e não ao referente; abandona qualquer teoria do sujeito, interessando-se somente pelas regras a que os sujeitos estão submetidos; pela forma, e não pelo conteúdo; e, principalmente, porque renuncia a qualquer tentativa de síntese.

Mas Foucault nunca chegou a ser realmente estruturalista. Sequer usa o termo estrutura, mas metáforas arqui- 
tetônicas: privilégio do espaço em detrimento do tempo (Billouet, 2003, p. 65). Ele jamais procurou estruturas atemporais, nem limitou suas pesquisas aos estados dos saberes; ao contrário, discutiu igualmente as suas transformações (Foucault, 2001e, p. 151). Embora, como os estruturalistas, Foucault ofereça uma visão do possível, não do exclusivo ou do irrefutável, ele não se interessa pela estrutura e pelo signo, mas pelo estudo da série e do evento, pela análise filosófica, e não pela análise semiológica. Foucault renuncia à interpretação. Para ele, o discurso vale em seu dito e em seu não dito, independentemente do pensamento ou da representação: o discurso enquanto prática que obedece a regras (regularidades), tanto no sentido sincrônico como no diacrônico (Foucault, 2004, pp. 182-ss).

A separação com a fenomenologia é maior, na medida em que Foucault não aceita o seu princípio básico: a ideia 242 do sujeito como aquele que confere sentido.

Tento [...] tomar distância da fenomenologia. Não penso que tenha havido uma espécie de ato fundador, pelo qual a razão em sua essência teria sido descoberta ou instaurada [...] penso que há uma autocriação da razão e por isto o que tento analisar são formas de racionalidade: diferentes instaurações, diferentes criações, diferentes modificações pelas quais as racionalidades se engendram umas às outras, se opõem e se perseguem umas às outras, sem que, no entanto, se possa assinalar um momento em que se teria passado da racionalidade à irracionalidade (Foucault, 2001d, p. 317).

\section{Nós, o sujeito}

O sujeito, a subjetivação e a objetivação são pontos essenciais do pensamento de Foucault. Mas, à diferença das correntes dominantes na pesquisa qualitativa, o que está no 
centro da sua forma de ver é o indivíduo, não o sujeito; o autor quer saber como o indivíduo moderno, enquanto sujeito e enquanto objeto, foi constituído. Foucault se interessa não pelo ator (o sujeito), mas pelos atos (as práticas) e pelos registros (os discursos).

Há nesta visão de uma subjetivação objetiva uma dupla dimensão: a primeira, a do indivíduo moderno como constituinte e constituído pelas práticas e pelo papel das teorias que se pretendem objetivas (dimensão analítica); a segunda, a da significação de que essas "objetividades" são investidas na nossa sociedade (dimensão interpretativa) (Dreyfus e Rabinow, 1992, p. 233).

A subjetivação, entendida como o processo de constituir uma subjetividade, leva Foucault a dois tipos de análise: a da objetivação, que se pergunta como os seres humanos se transformam em sujeitos (só existem sujeitos enquanto objetos) e a da relação com si, que procura dar conta de como nos transformamos em sujeitos da nossa própria existência. A partir destas indagações, Foucault descreve três modos de "subjetivação objetivizante” (Dreyfus e Rabinow, 1992, p. 155-ss):

1) a dos modos de investigação que se pretendem científicos (sujeito falante; sujeito produtivo);

2) a das práticas "divisionais", que cindem o indivíduo interna e externamente (são \& doente; cordato \& louco; criminoso \& honesto); e, finalmente,

3) a das técnicas de governabilidade, a investidura do sujeito pelo poder.

Esta concepção do sujeito, baseada em Nietzsche, é a mesma da do estruturalismo: o sujeito se constitui pela prática do poder, do saber e pelas técnicas de si; o sujeito é um objeto historicamente determinado.

Em As palavras e as coisas, Foucault demonstra como as ciências humanas (sociologia, psicologia, análise da lite- 
ratura e outros) vieram a constituir o sujeito moderno e, junto com a filosofia transcendental, criaram as condições de possibilidade da sua constituição. Como, entre o empírico e o filosófico, se constrói o sujeito-objeto da vida, do trabalho, da linguagem e do transcendental. Como o conhecimento científico constitui o sujeito, na medida em que o sujeito se torna objeto de conhecimento. Isto é, como se constitui a teoria do sujeito enquanto ser que vive, fala e trabalha.

Nas suas últimas pesquisas, notadamente nas que figuram na História da sexualidade, Foucault trata dos modos de subjetivação subjetivizantes (o relacionamento com si), do processo de escritura por si e para si (a desfragmentação do eu), a partir das anotações monásticas sobre a experiência espiritual (Foucault, 2001d). Ele passa da descrição arqueológica dos saberes sobre o sujeito para a descrição genealógica de práticas de dominação e de estra244 tégias de governabilidade e, no fim, à análise das técnicas da relação com o próprio sujeito; de como os indivíduos transformam-se e produzem-se.

O importante a reter sobre a questão do sujeito, para quem pretende seguir os passos epistemológicos de Foucault, é a postura de uma crítica radical do sujeito como consciência a-histórica, autoconstituída e absolutamente livre. Uma forma de dar conta da constituição dos saberes, dos discursos, dos domínios de objetos sem se referir a um sujeito.

\section{Um novo olhar}

A abordagem de Foucault é uma insurreição com vistas à libertação dos conteúdos históricos sepultados ou mascarados em coerências formais, nos modos de compreender do marxismo, da psicanálise, do estruturalismo. Ele não procura uma destinação nos acontecimentos, nas relações de força que se modificam, que se transformam, que se invertem. 
O objetivo das suas análises é, primeiramente, o estabelecimento das relações entre saberes, entendidos como positividades, com o que foi realmente dito e registrado. Depois, o autor se dedica à questão dos poderes e a outros temas, como o do corpo. Nas últimas obras, as práticas estarão referidas mais à consciência ética do que ao poder. É verdade que o estilo de Foucault desaparece ao mesmo tempo em que desaparece o método arqueológico (Billouet, 2003, p. 219). Mas em todas as investigações ele desenvolveu análises que aceitam, sem julgamento firmado a partir de uma crítica posterior e supostamente superior, a verdade do momento analisado e que buscam compatibilidades e incompatibilidades, que estabelecem regularidades, que permitem individualizar formações discursivas.

A sua forma de investigar nunca esteve presa a um roteiro; nunca admitiu uma mecânica ou um plano. A análise da loucura obrigou Foucault à análise do internamento, e esta à análise da prisão, que o levou a análise da justiça, e esta à do poder, que o obrigou à autoanálise do método e, no final, à análise da consciência de si e de todos nós. A modalidade de investigação que desenvolveu nos mostra que nem o sujeito, nem as motivações epistemológicas são a fonte, mas o produto das práticas sociais, de estratégias sem estrategistas, da compreensão de nós mesmos pela confrontação com o que já não somos (Muchail, 2004, p. 48).

Foucault nos lança para fora do conforto do espaço de trabalho, dos limites tacanhos da nossa erudição. O seu propósito foi o de estudar os saberes no seu entorno, de forma a revelá-los enquanto elementos da cultura ocidental e, a partir dos anos 1970, enquanto componentes essenciais do poder contemporâneo. Foucault é múltiplo: ele corrigia continuamente tudo que publicava; se colocava na vertical de si mesmo. Cada investigação, cada passo, transformava não só a obra, mas a ele mesmo. O seu olhar sabe tanto de 
onde olha quanto o que olha. É um olhar que problematiza, que elabora domínios de fatos, de práticas, de discursos que usualmente não consideramos como problemáticos. Uma análise crítica que procura ver como puderam ser construídas as diferentes soluções para um problema; mas, também, como essas diferentes soluções decorrem de uma forma específica de problematização (Foucault, 1984, p. 228).

Ao enfrentar a coerção do cientificismo, do discurso teórico, formal, unitário e científico, ao eliminar a tirania dos discursos englobantes, a abordagem de Foucault nos abre a possibilidade da objetividade material em que valem a prática social e não os indivíduos, a atualidade e não as origens, a verdade (mesmo que efêmera e mutável) e não as doutrinas.

Foucault nos ensina a construir a pesquisa como o jurista constrói a prova: partindo do que aí está, buscando os 246 seus elementos constituintes, discutindo-os até a conclusão que pareça inevitável. Mas ele não nos deixa esquecer que tudo isto é efêmero, que nós vivemos sem referências e sem coordenadas originárias, imersos em miríades de acontecimentos perdidos (Foucault, 1979).

\section{Hermano Roberto Thiry-Cherques}

é professor titular da Fundação Getúlio Vargas (RJ).

\section{Referências bibliográficas}

ALTHUSSER, L. 1987. Aparelhos ideológicos de Estado: nota sobre os aparelhos ideológicos de Estado. Rio de Janeiro: Graal.

BILLOUET, P. 2003. Foucault. São Paulo: Estação Liberdade.

CÁLAS, M.; SMIRCICH, L. 1999. "Past posmodernity? Reflections and tentative directions". Academy of Management Review, v. 24, no 4, pp. 649-671.

DELEUZE, G.; GUATTARI, F. 1976. O anti-Édipo: capitalismo e esquizofrenia. Rio de Janeiro: Imago. 
DREYFUS, H.; RABINOW, P. 1992. Michel Foucault: un parcours philosophique. Paris: Gallimard.

EWALD, F. 2004. La philosophie comme acte. Le Magazine Littéraire, no 435, oct., pp. 30-32.

FOUCAULT, M. 1977. Vigiar e punir. Petrópolis: Vozes. 1979. Microfísica do poder. Rio de Janeiro: Graal. 1998. O nascimento da clínica. Rio de Janeiro: Forense Universitária. 2001a. "A filosofia estruturalista permite diagnosticar o que é a 'atitude"”. In: Ditos e escritos, vol. II. Rio de Janeiro: Forense Universitária. 2001b. "Da arqueologia à dinástica". In: Ditos e escritos, vol. II. Rio de Janeiro: Forense Universitária.

2001c. "Entrevista sobre a prisão: o livro e seu método". In: Ditos e escritos, vol. $I V$. Rio de Janeiro: Forense Universitária.

2001d. "Estruturalismo e pós-estruturalismo". In: Ditos e escritos, vol. II. Rio de Janeiro: Forense Universitária.

2001e. "Michel Foucault explica o seu último livro". In: Ditos e escritos, vol. II. Rio de Janeiro: Forense Universitária. 2001f. História da sexualidade. Rio de Janeiro: Graal. 2002a. As palavras e as coisas. São Paulo: Martins Fontes. 2002b. História da loucura na Idade Clássica. São Paulo: Perspectiva. 2004. A arqueologia do saber. Rio de Janeiro: Forense Universitária.

HEIDEGGER, M. 1993. Basic writings: from being and time to the task of thinking. San Francisco: Harper and Collins.

HUSSERL, E. 2003. Idées directrices pour une phénoménologie pure et une philosophie phénoménologique. Paris: Presses Universitaires de France.

MACHADO, R. 1981. Ciência e saber: a trajetória da arqueologia de Michel Foucault. Rio de Janeiro: Graal.

MOTTA, F. C. P.; ALCADIPANI, R. 2004. "O pensamento de Michel Foucault na teoria das organizações”. Rausp, v. 39, no 2, abr.mai.jun., pp. 117-128.

MUCHAIL, S. T. 2004. "Um filósofo que pratica histórias". Cult, nํ 8, jun., pp. 47-48.

NIETZSCHE, F. 1990. A genealogia da moral. Lisboa: Guimarães Editores.

RIBEIRO, R. J. 2004. "Foucault, político”. Cult, no 81, jun., pp. 44-46.

ROWLINSON, M.; CARTER, C. 2002. "Foucault and history in organization studies”. Organization, vol. 9, no 4, nov., pp. 527-547. 
the most dynamic positions of the capitalist order in expansion, despite his low impact on the democratization of the system of domination in both contexts.

Key-words: Florestan Fernandes; Gino Germani; Immigrant; Sociology of modernization.

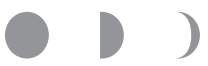

\section{À MODA DE FOUCAULT: UM EXAME DAS ESTRATÉGIAS ARQUEOLÓGICA E GENEALÓGICA DE INVESTIGAÇÃO}

\section{HERMANO ROBERTO THIRY-CHERQUES}

No texto apresento um programa para aplicação da forma de investigar de Michel Foucault às pesquisas em ciências humanas e sociais. A partir da exposição sobre as abordagens arqueológica e genealógica, desenvolvo um roteiro genérico de pesquisa. Discuto, a seguir, os principais instrumentos e conceitos epistemológicos utilizados por Foucault. Concluo com uma apresentação dos paralelismos entre a sua perspectiva e outras modalidades de investigação qualitativa.

Palavras-chave: Método; Foucault; Ciências humanas; Ciências sociais.

\section{LIKE FOUCAULT SENSE: AN EXAM OF THE ARCHEOLOGICAL AND GENEALOGICAL STRATEGIES OF INVESTIGATION}

In the text I present a program for aplication of Michel Foucault's form of investigation for researchs in human and social sciences. Whereof exposition about archeological and genealogical approaches, I develop a generical script of research. I argue, forward, the mainly tools and epistemological concepts used by Foucault. I conclude with a presentation of the parallelisms between his perspective and others types of qualitative investigation.

Keywords: Method; Foucault; Human sciences; Social sciences. 